\title{
Effect of zirconia addition on the fatigue behaviour of fine grained alumina
}

\author{
D BASU and B K SARKAR* \\ Central Glass and Ceramic Research Institute, Kolkata 700 032, India \\ *Indian Association for the Cultivation of Science, Kolkata 700 032, India
}

\begin{abstract}
The fatigue behaviour of fine grained $\mathrm{Al}_{2} \mathrm{O}_{3}$ and $\mathrm{ZrO}_{2}$ toughened $\mathrm{Al}_{2} \mathrm{O}_{3}(\mathrm{ZTA})$ compositions with 15 vol\% $\mathrm{ZrO}_{2}$ (3 mol\% $\mathrm{Y}_{2} \mathrm{O}_{3}$ stabilized: 3Y-TZP) have been investigated by using three different techniques. Primarily 4-point bending load was employed to generate tension-tension fatigue data under both static and cyclic conditions. The results clearly showed that the materials were susceptible to both the static and cyclic fatigue and the time to failure under cyclic loading was considerably shorter than the equivalent static loads. The repeated indentations at the same spot with varying loads showed a typical fatigue behaviour. In addition, both the materials were subjected to the repeated impact cycles at varying subcritical loads simulating impact fatigue. In all the cases typical fatigue curves were obtained having a progressive endurance at subcritical loads having an endurance limit. The fatigue behaviour of $\mathrm{Al}_{2} \mathrm{O}_{3}$ was much improved by the addition of 15 vol\% 3Y-TZP, having micro-plasticity contributing towards the cyclic fatigue phenomena of these materials.
\end{abstract}

Keywords. Fatigue; static/cyclic loading; microplasticity.

\section{Introduction}

The failure under fatigue conditions, at loads much below the critical failure strength is a common phenomena in all the materials including ceramics. The pioneering observation of Gernet (1899) on the strength dependence of glass on the rate of loading remained unexplained for nearly half of a century till Charles (1961) and others (Hillig 1962; Phillips 1965) explained the stress related chemical reactions between water vapour and glass surface. Pearson (1950) claimed that the deterioration in strength under static fatigue of $\mathrm{Al}_{2} \mathrm{O}_{3}$ too was dependent on the combined effect of moisture and stress. Krohn and Hassleman (1972) demonstrated a thermally activated process in the cyclic fatigue of $\mathrm{Al}_{2} \mathrm{O}_{3}$. Ko $(1986,1989)$ correlated the static bending and fatigue strength of sintered $\mathrm{Al}_{2} \mathrm{O}_{3}$ by an $\mathrm{S}-\mathrm{N}$ curve generated from the experimental values. Guiu and co-workers (Guiu and Vaughan 1986; Vaughan and Guiu 1987; Vaughan et al 1987; Reece and Guiu 1990) introduced a novel technique to study the tribological effect under normal/fluid environment on the fatigue properties of bio-grade $\mathrm{Al}_{2} \mathrm{O}_{3}$. Attempting to stimulate the fatigue conditions, they performed repeated indentations with varying subcritical loads on the same position having a pre-indentation with a higher load till chipping occurred. Thus an S-N curve was constructed which differed from the similar curves obtained by cyclic loading. Several workers (Sarkar and Glinn 1969; Huffine and Berger

\footnotetext{
*Author for correspondence
}

1977; Maity et al 1994) have demonstrated the susceptibility of $\mathrm{Al}_{2} \mathrm{O}_{3}$ ceramics to an impact fatigue and explained that the stresses induced by shock were more damaging.

It has been widely reported (Pabst et al 1980; Becher 1983; Orange et al 1988) that the static fatigue parameters of $\mathrm{Al}_{2} \mathrm{O}_{3}$ was significantly improved by $\mathrm{ZrO}_{2}$ addition but for the cyclic fatigue the effect was not significant. It has been recently claimed (Mencik 1984) that the toughening mechanism operative in $\mathrm{ZrO}_{2} / \mathrm{Al}_{2} \mathrm{O}_{3}-\mathrm{ZrO}_{2}$ systems imparting a crack resistance $(R)$ curve often results into a poor resistance to the cumulative damage of cyclic fatigue. A clear understanding of the degradation behaviour however, has not been developed.

In the present paper the fatigue behaviour of $\mathrm{Al}_{2} \mathrm{O}_{3}$ reinforced with 15 vol\% $3 \mathrm{Y}$-TZP under the 4-point bending, indentation under both static and cyclic conditions and repeated impact loading were investigated. The fatigue properties of both the materials were compared. An attempt was made to correlate the fatigue resistance parameters arising out of the different techniques adopted to explain the fatigue behaviour of such materials.

\section{Experimental}

\subsection{Specimens}

$\mathrm{Al}_{2} \mathrm{O}_{3}$ (XA-16, USA) powder of $0.7 \mu \mathrm{m}$ size was mixed with 15 vol\% $\mathrm{ZrO}_{2}$ partially stabilized with 3 vol\% $\mathrm{Y}_{2} \mathrm{O}_{3}$ (3Y-TZP) (Toyosoda Corporation, Japan) having $0.2 \mu \mathrm{m}$ 
and milled in a planetary mill for $4 \mathrm{~h}$ in isopropanol medium. The mixture was subsequently dried and calcined at $700^{\circ} \mathrm{C}$ and reground with an addition of polyvinyl alcohol. The mixed powder was uniaxially compacted into $55 \times 55 \times 5 \mathrm{~mm}$ bars at $100 \mathrm{MPa}$ followed by isostatic compression at $150 \mathrm{MPa}$. Green cylindrical samples were prepared for the impact fatigue studies. The samples were presintered at $800^{\circ} \mathrm{C}$ and finally sintered at $1550^{\circ} \mathrm{C}$ for $1 \mathrm{~h}$. The sintered grain sizes of $\mathrm{Al}_{2} \mathrm{O}_{3}$ and $\mathrm{ZrO}_{2}$ were $1-3 \mu \mathrm{m}$ and $0.3-0.4 \mu \mathrm{m}$ respectively. The sintered density was measured by the water displacement method. The transverse flexural strengths (TRS) were measured on a 4-point bending fixture with a stressing rate of $10 \mathrm{MPa} \mathrm{sec}-1$ using 1185 Instron machine. Hardness was measured using a Vicker's hardness tester. The Young's modulus was estimated by an ultrasonic velocity measurement using Kraut Kramer USIP 12 tester interfaced with a Philips 3350, $100 \mathrm{MHz}$ Oscilloscope. The fracture toughness, $K_{\mathrm{IC}}$, was determined from the length of the cracks generated at the corners of the Vicker's indentation with different loads from

$$
K_{\mathrm{IC}}=0 \cdot 016(E / H)^{1 / 2} P \cdot C^{-3 / 2},
$$

where $E$ is the Young's modulus, $H$ the hardness, $P$ the indentation load, and $C$ the crack length. The properties of the sintered composite specimens compared with $\mathrm{Al}_{2} \mathrm{O}_{3}$ is given in table 1 .

\subsection{Static and cyclic fatigue}

The static fatigue behaviour with constant load was studied on a 4-point bending fixture in an electro-servo hydraulic Instron machine of $20 \mathrm{KN}$ capacity. The corresponding failure time for each subcritical applied load was recorded for an S-T plot. The specimen were loaded at the rate of $2 \mathrm{~N} / \mathrm{sec}$ up to a predetermined level and during the operation the instrument was kept under load control mode with a narrow range. The cyclic fatigue was studied under a sinusoidal stress wave form within a stress ratio of 0.5 and frequency of $5 \mathrm{~Hz}$. The mean value of the cyclic stress was maintained identical with the static stress. A computer software recorded all

Table 1. Physical properties of sintered $\mathrm{Al}_{2} \mathrm{O}_{3}$ and $\mathrm{Al}_{2} \mathrm{O}_{3}+15$ vol\% 3Y-TZP $\mathrm{ZrO}_{2}$.

\begin{tabular}{|c|c|c|}
\hline Properties & $\mathrm{Al}_{2} \mathrm{O}_{3}$ & $\mathrm{Al}_{2} \mathrm{O}_{3}+\mathrm{ZrO}_{2}(\mathrm{ZTA})$ \\
\hline Sintered density (g/cc) & 3.95 & $4 \cdot 26$ \\
\hline Porosity $(\%)$ & $<1.0$ & $<2 \cdot 0$ \\
\hline $\begin{array}{l}\text { Transverse rupture strength } \\
\text { (MPa) }\end{array}$ & 290 & 775 \\
\hline Fracture toughness $\left(\mathrm{MPa} \cdot \mathrm{m}^{1 / 2}\right)$ & $3 \cdot 5$ & $5 \cdot 7$ \\
\hline Hardness $(\mathrm{GPa})$ & 17.8 & 17.0 \\
\hline Young's modulus (GPa) & 380 & 320 \\
\hline
\end{tabular}

the load deflections data along with the number of cycles required for fracture.

\subsection{Indentation fatigue}

The repeated indentations with $300,200,156 \cdot 25,100,50$ and $30 \mathrm{~N}$ loads were made on the same spot of the specimen with a Vicker's hardness indenter. The experiments were repeated five times for each load maintaining indentation for $60 \mathrm{sec}$ and the corresponding number of cycles to chipping was noted for an S-N plot.

\subsection{Impact fatigue}

A modified Charpy impact tester with a swinging pendulum was designed and constructed for the repeated impact (fatigue) test similar to Sarkar and Glinn (1969) and Maity et al (1994). A pendulum length of $38.3 \mathrm{~cm}$ and a hammer weight of $0.2358 \mathrm{~kg}$ were used in the present investigation. The impact energy, $E_{1}$ was calculated by using

$$
E_{1}=m g h(1-\cos \theta)
$$

where $m$ is the mass of the hammer, $g$ the gravitational constant, $h$ the height of pendulum and $\theta$ the angle of release of the hammer. Energy losses due to friction, windage, and toss losses were calibrated with a broken specimen held between the grips, from the differences between the angle of release and the angle of the final upswing of the hammer. Considering the failure to be under tension at the bowed and the impact stress $\sigma$, it was calculated from the modification of the equation proposed by Timoshenko and Young (1968). Thus,

$$
\sigma=P / A+\left(P^{2} / A^{2}+2 E_{\mathrm{i}} \cdot E / A \cdot l\right)
$$

where $E$ is the Young's modulus, $P$ the load, $A$ the crosssection of the specimen, $l$ the length of the specimen.

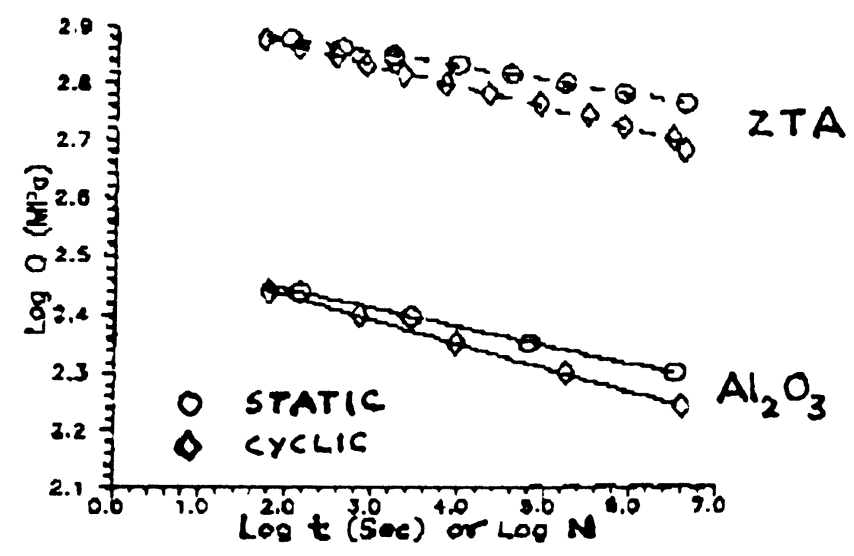

Figure 1. Static and cyclic fatigue of $\mathrm{Al}_{2} \mathrm{O}_{3}$ and ZTA with 15 vol\% 3Y-TZP. 


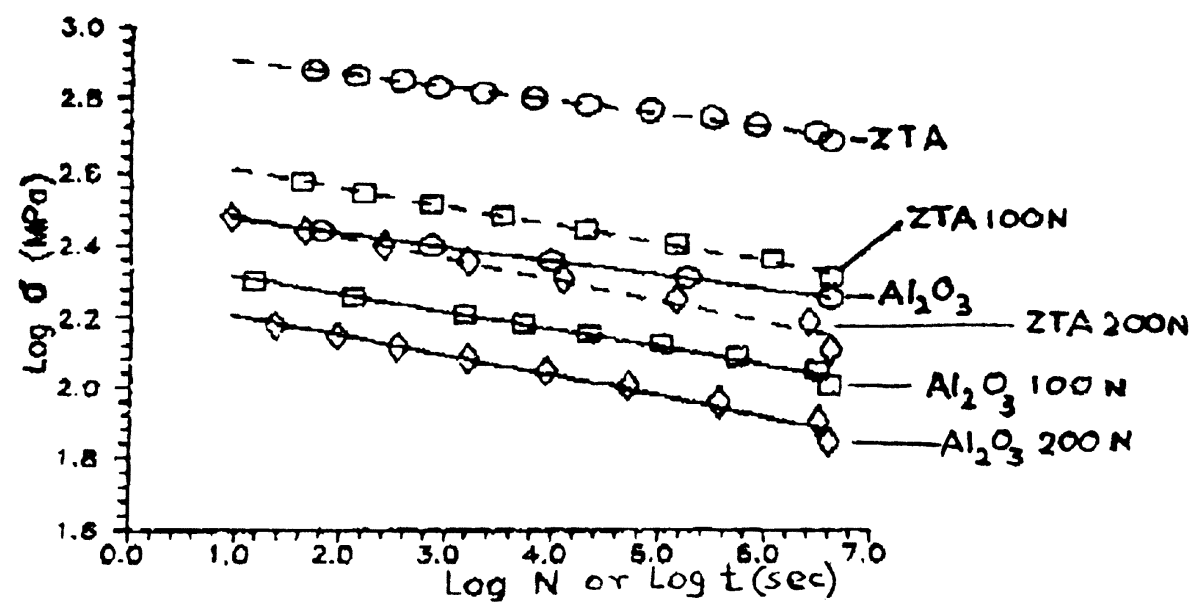

Figure 2. Static and cyclic fatigue of ZTA with 3Y-TZP revealing the effect of indentation cracks generated in the system.

The critical single blow impact strength was determined from the release of the hammer from the highest angle at which the sample broke, thereafter the angle was reduced at $5^{\circ}$ intervals and the number of impacts endured was noted to plot an $\mathrm{S}-\mathrm{N}$ curve. The frequency of impacts was set at 8 impacts/min.

\section{Results and discussion}

Figure 1 represents the results of the static and cyclic fatigue of $\mathrm{Al}_{2} \mathrm{O}_{3}$ and $3 \mathrm{Y}-\mathrm{TZP} \mathrm{ZrO}_{2}$ reinforced $\mathrm{Al}_{2} \mathrm{O}_{3}$. The logarithm of the constant stress in case of the static tests or the peak $\left(\sigma_{\max }\right)$ in the cyclic tests is plotted against the logarithm of both time, $t$ and number of cycles, $N$ to failure.

The experimental data was thus fitted to a relationship

$$
\log \sigma_{\max }=1 / n \log N(\text { or } t)+C
$$

where $C$ is a constant and $n$ the fatigue resistance parameter. It was apparent that $n$ for static and cyclic conditions for $\mathrm{Al}_{2} \mathrm{O}_{3}$ increased from 30 to 25 to 39 and 27 respectively by the additions of $\mathrm{ZrO}_{2}$ in agreement with the observations made by Guiu and others (Guiu 1978; Reece et al 1989). The results of the indentation fatigue with 100 and $200 \mathrm{~N}$ loads for both the static and cyclic conditions are shown in figure 2.

It was revealed that in the case of the static loading on both the materials the fatigue resistance parameter or the endurance limit to the breaking stress ratio did not change significantly and the moderate deviation was well within the scatter of the data points. The above two parameters varied widely during cyclic loading particularly for the composition with the 3-YTZP although no clear-cut trend was visible. In this material the cyclic fatigue limit was 27 , while the specimen with Vicker's indent of $100 \mathrm{~N}$ $(c=131 \mu \mathrm{m})$ and $200 \mathrm{~N}(c=205 \mu \mathrm{m})$ were 20 and 18

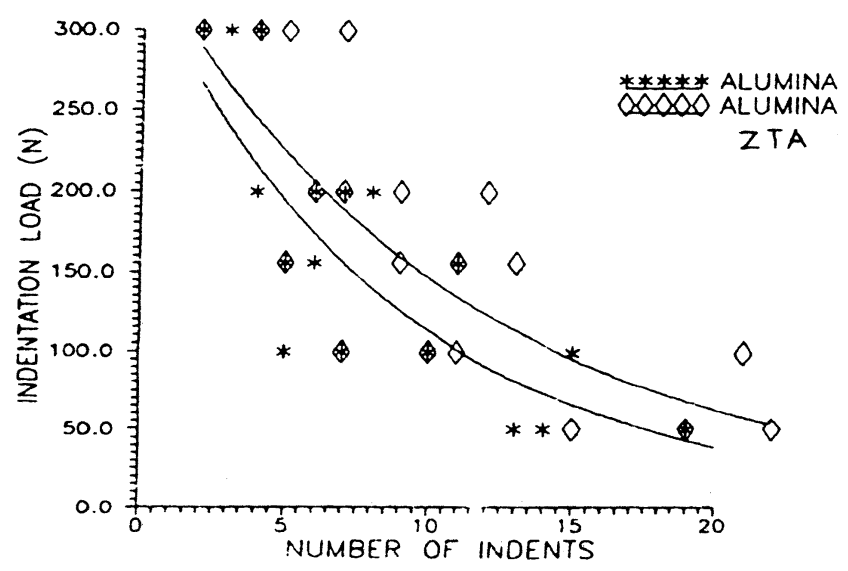

Figure 3. Dependence of chipping on indentation load for $\mathrm{Al}_{2} \mathrm{O}_{3}$ and $\mathrm{ZTP}$ with 15 vol\% $3 \mathrm{Y}$-TZP.

respectively. Similarly the endurance limit to the breaking stress ratio for this material without preindentation was 0.726 and 0.629 which was reduced to 0.664 and 0.538 , 0.697 and 0.451 when indented with the Vicker's indent of $100 \mathrm{~N}$ and $200 \mathrm{~N}$ respectively.

The differences in the indentation fatigue behaviour between the two materials is well demonstrated in figure 3 . It indicates that although the number of indentation cycles required to produce chipping increased with decrease in indentation load but this dependence was small in comparison to the conventional fatigue data. Further, the wide scatter in the data restricted any clear interpretations. Figure 4 represents the result of the repeated impact tests on $\mathrm{Al}_{2} \mathrm{O}_{3}$ and $\mathrm{ZTA}$.

Both the materials demonstrated a clear $\mathrm{S}-\mathrm{N}$ curve which was in agreement with the findings of Sarkar and Glinn (1969). The mechanism of such a fatigue failure had been discussed (Maity et al 1994). The $n$ value of $5 \cdot 5$ for $\mathrm{Al}_{2} \mathrm{O}_{3}$ obtained by them was less than the value 14 obtained from the static and cyclic loading in the present 


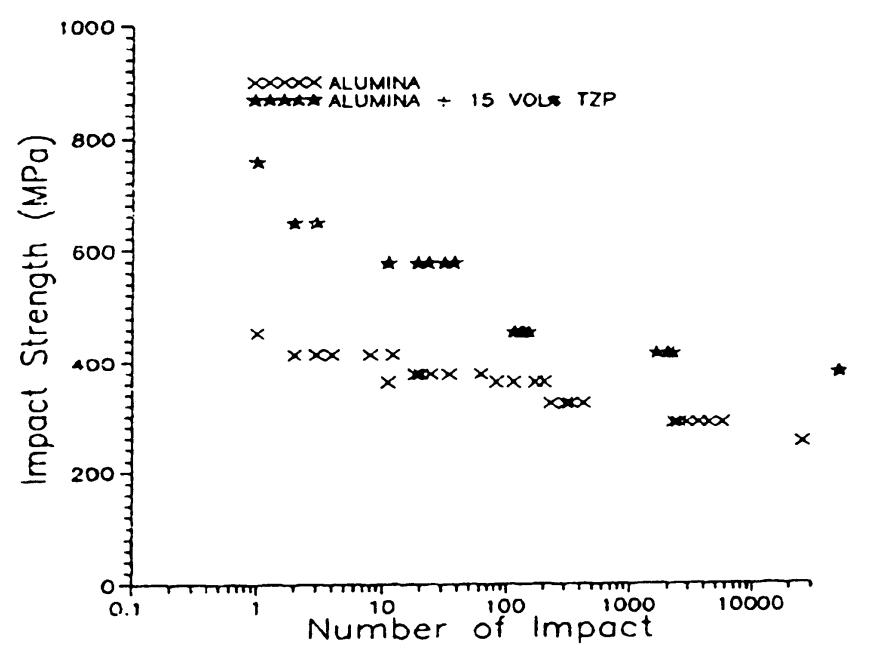

Figure 4. Impact fatigue of $\mathrm{Al}_{2} \mathrm{O}_{3}$ and $\mathrm{ZTA}$ with 15 vol\% 3Y-TZP.

investigation. The reason could be attributed to the purity of the material. Our material had a purity of $99.7 \%$ against $96 \%$ of Sarkar and Glinn (1969). The results further indicated that although 3Y-TZP additions improved the endurance limit of the composite samples from 270.5 to $395.5 \mathrm{MPa}$ with an improved strength but the fatigue resistance parameter did not change. The fatigue ratio (the ratio between the endurance limit and single impact strength) however, decreased from 0.71 for $3 \mathrm{Y}-\mathrm{TZP}$ to 0.52 for $\mathrm{Al}_{2} \mathrm{O}_{3}$ imperative of the former being more prone to failure by a sudden shock.

\section{Conclusions}

The addition of 15 vol\% $3 \mathrm{Y}-\mathrm{TZP}$ in $\mathrm{Al}_{2} \mathrm{O}_{3}$ had increased the static fatigue resistance parameter ' $n$ ' from 30 to 39 , and so did the endurance limit. The improvement from 25 to 27 in cyclic fatigue was, however, marginal. Indentation fatigue revealed an $\mathrm{S}-\mathrm{N}$ type curve having a progressive endurance with decreasing subcritical loads having an endurance limit, the magnitude of which depended on the pre-applied indentation load. Strengthening $\mathrm{Al}_{2} \mathrm{O}_{3}$ with TAP improved the fatigue behaviour.

Impact fatigue studies also demonstrated a typical S-N behaviour having $n=14$ for both the materials. The endurance limit of the composite was improved from $270 \cdot 5$ to $395 \cdot 5$. The fatigue ratio was lower than that pure $\mathrm{Al}_{2} \mathrm{O}_{3}$. The static fatigue behaviour of these materials was superior to the cyclic fatigue. While moisture has been attributed for the static fatigue phenomena the susceptibility to the cyclic fatigue is a clear evidence of the existence of micro-plasticity, over and above the role played by moisture, in contributing to the failures under fatigue.

\section{Acknowledgements}

The authors are grateful to CSIR, New Delhi, for providing the necessary funds. Dr $\mathrm{R} W$ Steinbrach, Energietechnik Forschungszentrum, Julich, Germany, is acknowledged for providing facilities to conduct mechanical and indentation fatigue studies.

\section{References}

Becher P F 1983 J. Am. Ceram. Soc. 66483

Charles R J 1961 Progress in ceramic science (ed.) J E Burke (New York: Pergamon Press) vol. I

Davidson D L, Campbell J B and Lankford J 2001 Acta Metall. (in press)

Evans A G and Fuler E R 1974 Met. Trans. 527

Green D J 1982 J. Am. Ceram. Soc. 65610

Grenet L 1899 Bull. Soc. Enc. Industr. Nat. Paris 4838

Guiu F 1978 J. Mater. Sci. 131957

Guiu F and Vaughan D A J 1986 Proc. advanced ceramics (eds) J S Moya and S de Aza (Madrid, Spain: Sociedad Espanola de ceramica Y Vidrio)

Guiu F, Reece M J D and Vaughan A J 1991 J. Mater. Sci. 26 p 3275

Hillig W B 1962 Modern aspects of the vitreous state (ed.) J D Mackenzie (Washington DC: Butterworth Inc) vol. 2

Hori S K, Yoshimura M and Sōmiya S 1986 J. Am. Ceram. Soc. 69169

Huffine C L and Berger C M 1977 J. Am. Ceram. Soc. Bull. 56 201

Ko H N 1986 J. Mater. Sci. Lett. 5464

Ko H N 1989 J. Mater. Sci. Lett. 8438

Krohn D A and Hasselmann D P H 1972 J. Am. Ceram. Soc. 55 208

Liu S Y and Chen I W 1991 J. Am. Ceram. Soc. 741206

Maity S, Basu D and Sarkar B K 1994 Mater. Lett. 2163

Mencik J 1984 J. Am. Ceram. Soc. 6737

Orange G, Fantozzi G, Homerin P, Thevenot F, Leriche A and Cambier F 1988 Advances in ceramics: Science and technology of zirconia III (eds) S Sōmiya and N Yamamoto $\mathbf{2 4}$

Pabst R F, Bognar I and Claussen N 1980 Sci. Ceram. 10 603

Pearson S 1950 Royal Aircraft Establishment Report p. 51

Phillips C J 1965 A M Scientist 5320

Reece M J and Guiu F 1990 J. Am. Ceram. Soc. 731004

Reece M J, Guiu F and Sammur M F R 1989 J. Mater. Sci. 72 348

Sarkar B K and Glinn T G J 1969 J. Mater. Sci. 4951

Timoshenko S P and Young D H 1968 Elements of strength of materials (New York: Littleton Educational Publishing Inc)

Vaughan D A J and Guiu F 1987 Engineering with ceramics (eds) R Freer, S Newman and G Syers (Shelton Stoke-onTrent, UK: Institute of Ceramics) 2

Vaughan D A J, Guiu F and Dalmau M R 1987 J. Mater. Sci. Lett. 689 